\title{
Urine Diversion Dry Toilet: A Narrative Review on Gaps and Problems and its Transformation
}

\author{
Govinda Prasad Devkota $^{1 *}$, Manoj K. Pandey ${ }^{2}$, Shyam Krishna Maharjan ${ }^{3}$ \\ ${ }^{1} \mathrm{PhD}$ Research Scholar, Graduate School of Education, Tribhuvan University, Nepal \\ ${ }^{2}$ Faculty of Environmental Sciences and Natural Resource Management, Norwegian \\ University of Life Sciences, Norway \\ ${ }^{3}$ Central Department of Education, Tribhuvan University, Nepal
}

\section{ARTICLE INFO}

Keywords:

Eco-San Toilet

Nutrients

School Education

Transformation

\begin{abstract}
This review paper highlights the gaps and problems on source separation of human excreta; implementing and adopting human urine as nutrients for agriculture. The objective of the paper is to appraise the historical context behind the promotion of Urine Diversion Dry Toilet/Eco-san toilet and its relevance in rural Nepalese context. Moreover, it highlights the experiences regarding agricultural perspectives and livelihood by applying human urine as a fertilizer. Furthermore, it helps to understand and analyze the major issues, gaps and problems in acceptance and use of human excreta in Nepalese context for scaling up of its application and its transformation through school education system. Database search based on 'Free text term' or key word search was the strategy used to map of all relevant articles from multiple databases; Medline (1987-2018), MeSH (2005-2018), CINAHL (1998-2018) and OvidMedline (1992-2019). For each the outputs were downloaded into RefWorks databases. Specifically, this paper focuses on urine diversion to demonstrate its potential to elegantly separate and collect as nutrients and desire to control pathogens and micropollutants help in sanitation. It is recommended that an urgent need to participate community people and school children to disseminate users' perceptions, attitudes and behaviour concerning the urine diversion toilets.
\end{abstract}

\section{Introduction}

A urine-diverting dry toilet (UDDT) is a type of dry toilet with urine diversion that can be used to provide safe, affordable sanitation in a variety of contexts worldwide (Rieck et al., 2012). Through the separate collection of feces and urine without any flush water, many advantages can be realized, such as odor-free operation and pathogen reduction by drying. While dried feces and urine harvested from UDDTs can be and routinely are used in agriculture, many UDDTs installations do not make use of any sort of recovery scheme (McConville \& Rosemarin, 2012). The UDDT is an example of a technology that can be used to achieve a sustainable sanitation system. Similarly, this eco-san /UDDT innovation is appropriate where connection to a sewer system and centralized waste water treatment plant is not feasible or desired. This system is more feasible to that place where fertilizer and soil conditioner are needed for agriculture, or groundwater pollution should be minimized.

* Corresponding author E-mail address: devkotagovinda11@gmail.com 
There are several types of UDDTs: the single vault type which has only one feces vault; the double vault type which has two feces vaults that are used alternately; and the mobile or portable UDDTs which are a variation of the single vault type and are commercially manufactured or homemade from simple materials. A UDDT can be configured as a sitting toilet (with a urine diversion pedestal or bench) or as a squatting toilet (Von Munch, $\&$ Winker, 2011). The most important design elements of the UDDT are: source separation of urine and feces; waterless operation; and ventilated vaults (also called "chambers") or removable containers for feces storage and treatment. If anal cleansing takes place with water (i.e., the users are "washers" rather than "wipers"), then this anal cleansing water must be drained separately and not be allowed to enter the feces vault.

A dry cover material is usually added to the feces vault directly after each defecation event. The dry cover material may be ash, sawdust, soil, sand, dried leaves, mineral lime or compost. Dried and decomposed feces collected in a UDDT after prudent storage and treatment can also be used as a cover material. The cover material serves to improve aesthetics, control flies, reduce odor and speed up the drying process.

\subsection{Evolution of UDDT in Nepal}

The current global trend of urbanization is creating pressure on Nepal's eco-system. Nepal is also struggling with the most rapid urbanization trend in the South Asian sub-continent, with around $15 \%$ of its total population living in 58 designated urban areas. This figure is expected to reach $23 \%$ by 2020 because the urban population is increasing at $6.6 \%$ a year, reflecting an increase in migration to towns as an escape from rural poverty, conflict and the reclassification of emerging towns from villages to municipalities (WHO/UNICEF, JMP, 2017). Present sanitation coverage in Nepal indicates that only around $46 \%$ of the total population has access to some kind of latrine facilities (Adhikari et al., 2017). The scale of the problem is further illustrated by the present achievement made by the country to meet the Sustainable Development Goal (SDG) targets 6. The toilets constructed in some parts of the country often fail to meet required level of hygienic standard. The challenge is to increase the toilet coverage and its accessibility by increasing the depth of understanding among communities to ensure sustained use and hygiene behavior. In all circumstances, a toilet must be hygienic, safe, environmentally friendly and affordable (WHO/UNICEF, JMP, 2017).

In Nepal, UDDT/Eco-san toilet technology was piloted in 2002 with the implementation of Double Vault urine diverting dry toilets in Khokana (Rajbhandari, 2008). That programme was well accepted and admired by the community as they had two advantages. Firstly, it provided improve latrine facilities and, secondly, because the human waste produced therein was recoverable and recyclable, creating a valuable resource for agricultural needs. This was for the first time in Nepal that latrines were linked to economic benefits and livelihood opportunities for people. With the success of the pilot programmes (DWSS, 2012), the Ecosan latrine technology was gradually promoted to various other parts of urban and semi-urban areas of Nepal by many leading organizations including: Water Aid Nepal (WAN) through partners such as Environment and Public Health Organization (ENPHO), Support Group for Shelter (LUMANTI), Centre for Integrated Urban Development (CIUD), Nepal Water for Health (NEWAH), and Department of Water Sanitation and Sewerage (DWSS). During the pilot stage, Thimi Municipality was engaged with NEWAH in promoting this type of technology. The Nepalese government recognized the Eco-san toilet as one of the most important and inevitable sanitation options available and suggested, in its paper on sanitation, that Eco-san needs to be promoted (Bell, 2014). This technology is also being gradually piloted in rural areas of Nepal by ENPHO and DWSS, with slight modifications in the concept and design. Based on the acceptance of the technology by the rural community, 
ENPHO, DWSS and other agencies are also trying to replicate this modified Eco-san toilet technology in rural areas, under the name: UDDT (Water Aid, 2008).

\subsection{The Nutrient Value for Agricultural production from UDDT}

People throughout history have used feces and urine for agricultural purposes as they have recognized the positive qualities of these so-called wastes (Winblad \& Herbert, 1998).

The nutrients contained within feces and urine are frequently better than the commercial fertilizers being applied at great cost to crops throughout the world. Too many poor families and individuals, commercial fertilizers are, in any case, unaffordable. Even if commercial fertilizers were cheaper and easily accessible to the poor, other hard questions are being asked about the long-term consequences of commercial fertilizer application such as the dangers of polluting rivers and reduction in the carrying the capacity of the land over time.

Theoretically, the nutrients in domestic wastewater are almost sufficient to fertilize all the crops needed to feed the world population (Simha, \& Ganesapillia, 2017). As much as 80$90 \%$ of the major plant nutrients (nitrogen, phosphorous and potassium) in wastewater are present in the toilet waste. If these nutrients are reclaimed using hygienically safe pathways, they can be used locally as a fertilizer in suitable agricultural production (Bonvin et al., 2015).

A theoretical analysis revealed that one person contributed about 30 gram per day Biological Oxygen Demand (BOD) equivalent organic waste. One $\mathrm{kg} \mathrm{BOD} \mathrm{produces} 14 \mathrm{~kg} \mathrm{CO}_{2}$ aerobic process and $1.68 \mathrm{CO}_{2}$ in anaerobic process with gas used. One $\mathrm{kg}$ of BOD produces $0.68 \mathrm{~kg}$ $\mathrm{CO}_{2}$ and $0.25 \mathrm{~kg} \mathrm{CH} 4$ (Wilbur, 2014). Considering widely used on site pit system as bare line, relative carbon emission of other system is same in anaerobic pond, 69\% mechanical aeration process, $29 \%$ in bio-gas system and $24 \%$ in natural oxidation system (DWSS, 2012). One person produces feces that are about 30 gram of BOD equivalent. Considering that one $\mathrm{kg}$ BOD makes emission of about $0.68 \mathrm{~kg}$ carbon dioxide and $0.25 \mathrm{~kg}$ methane gas per $\mathrm{kg}$ and considering climate change factory of methane as 20 times carbon emission of one person in a year become $62 \mathrm{~kg}$. If feces are used as fertilizer/ soil condition, then emission that would occur in pit can be considered as avoided by using eco-san toilet.

Hence, total carbon dioxide emission that can be saved by use of eco-san system is about $107 \mathrm{~kg}$ per person per year (DWSS, 2012). Through the separate collection of feces and urine without any flush water, many advantages can be released, such as odor-free operation and pathogen reduction by drying (Adeoluwa, \& Cofie, 2012) while dried feces and urine harvested from UDDT can be used routinely in agriculture as a soil amender and nutrientrich fertilizer (Yongha et al., 2013). The UDDT is an example of technology that can be used to achieve a sustainable sanitation. These dry excreta management system is an alternative to pit latrines and flush toilets especially where water is scare, fertilizer and soil conditioner are needed for agriculture or groundwater pollution should be minimized (Esrey et al., 1998).

The agenda in terms of sanitation and health in its push for sustainable development has neglected in the world. Despite all efforts, sanitation strategies and program in developing countries like Nepal have often been challenged by the emerging complex nature of individual social and environmental barriers (Dreibelbis et al., 2013).

In order to reach the SDG (6) and achieve sustainability in the field of waste water management and sanitation, a new paradigm is clearly needed (Simha, \& Ganesapillai, 2017) in sanitation must be based on ecosystem approaches. Sanitation systems are part of several cycles, of which the most important cycles are the pathogen, water nutrient and energy cycle (Bonvin et al., 2017).

In order ensure public health, sanitation approaches primarily aim at interrupting the life cycle of the pathogens. In addition, the new approach is recognizing human excreta and water from households not as a waste but as a resource (Abraham, et al., 2011). Human excreta and 
manure from play an essential role in building healthy soils and provide valuable nutrients for plants. This approach, mostly addressed as eco-san offers an alternative to conventional sanitation. It carries with it a new approach to sanitation education, a new discourse, and a new way of managing knowledge (Von, \& Winker, 2009).

\section{Methods}

This review article is based on electronic research data, and synthesized published grey literature such as research articles, essays, case reports and manuals published in peer and non-peer reviewed journals. It is an intentional and coherent approach to analyzing data across qualitative studies. The search strategy in this review involved systematic electronic database searching, hand searching and grey literature searching. 'Free text term' or 'key word search' was the first strategy used to map of all relevant articles from multiple databases; Medline (1987-2018), MeSH (2005-2019), CINAHL (1998-2018) and OvidMedline (1998-2017). For each search, the outputs were downloaded into crossref works database and screened later following the inclusion criteria (i) original research or systematic review; (ii) search had to in the title, abstract or key words on the database in terms of ecosan innovation and application of human urine has been done. Books, book reviews, editorials, reports and news articles identified from other sources were also added to the review. The citations were initially screened on title and those retained were screened again their abstracts.

Inclusion and exclusion criteria based on the key terms, ecological sanitation, human urine application, participatory action research, urine diversion etc. were used in database which helped to eliminate studies that are not aligned with the research questions. The synthesized evidence from content or thematic analysis is relatively effective to present it in the review. The comprehensive search with synthesize the evidence clearly outlined and rigorously reviewed. This synthesis information is user-friendly format and presents a broad perspective on a subject, its development and management.

\section{Results}

\subsection{Issues and Challenges of UDDT/ Eco-san Toilets}

Despite of having good nutrient value, human urine requires careful application. If urine is not applied carefully, it can cause volatilization of intrinsic ammonia (a greenhouse gas), increase soil conductivity, salinity and phosphorus $(\mathrm{pH})$, poor agro- productivity or in some instances, crop failures (Heinonen et al., 2007). Large urine collection, handling, storage and transportation to farm-land is another challenge.

The further concern in UDDTs is cross- fecal contamination of the relative sterile and sourceseparated urine. The contaminated urine may carry pathogens like Enterococcus, Escherichia coli, salmonella, helminthes ova such as Ascarsis, Rotavirus and bacteriophages (Nyberg et al., 2014).

\subsection{Political interference}

A study entitled 'Assessment of Eco-san Toilet in Nepal' showed that the interests between community people and government authority on implementation of eco-san toilet/UDDT application in school and community had different views, like community wanted to apply Eco-san toilet whereas government forced to supplying human waste through drain. In some cases, elected officials have a good overview of their constituencies and the demands and needs of different communities. In other cases, political involvement is not in the best interest of the programme and will not improve the programme credibility (Bell, 2014).

\subsection{Equity in participation}


In all environments, the participation on cleanliness among children, family head and other family members did not find equal participation. Not only in community setting but also school setting, it was found that there was no equal participation among teachers, students and other staff. Similarly, it can make a great difference whether a child is born into socially more respected class or in a poor or minority household (Kumwenda, 2019). Schools and governments often prefer not to mention inequalities. However, keeping silent about social and economic differences perpetuates inequalities. The only way governments, districts, schools, teachers and children can deal with inequalities is by recognizing them and seeking solutions that are fair for everyone. Approaches that are sensitive to issues of gender, class, and ethnic group and income-level can help school water. In the school and sanitation projects succeed in achieving their objectives for all girls and boys, men and women, richer and poorer members of the community (Rai et al., 2015)

\subsection{Connecting with the community}

The challenge is to make best use of the interrelationship between the school and the community for improved sanitation and hygiene. Links with the community are important for many reasons:

(a) Improving school sanitation and hygiene makes no sense if most children cannot practice hygiene at home (Mayo \& Mubarak, 2014); (b) children are in general highly motivated to improve conditions and practices at home and in their communities and thus can be excellent catalysts for positive change; (c) school events (e.g. parents' days) and students' assignments (e.g. simple surveys in their homes, neighborhoods and community) are excellent opportunities to raise awareness and initiate community projects on subjects such as environmental protection and improved water supply and sanitation; (d) schools need the assistance of parents and local administrations and organizations to establish and sustain good facilities (Wendland, \& Jorritsma, 2011).

\subsection{Acceptance and non-acceptance of UDDT}

UDDT is a permanent asset of households and communities. However, the sustainability of the UDDTs depends in users' acceptance, use and maintenance. UDDT system is to minimize environmental and health risk related to inadequate and poor sanitation. UDDT technology is based on the assumption that keeping urine and feces separate destroys the disease causing pathogens contained in the fecal matter overtime, though a drying process (Tilley, Ulrich, Lüthi, Reymond, \& Zurbrïgg, 2014). Study conducted by Nosipho (2017) found that the acceptance for UDDT was higher in younger participants compared to other older participants. Younger participants also seem to have greater awareness as to why it was installed compared older participants.

With regard to the excessive use of UDDT it was found that the parents discouraged their children from using UDDT and they practice open defection instead. The main reason was that they were scared that the child might fall into the toilet pits. A crucial factor in user satisfaction is the absence of smell. It was the predominant reason for the non-acceptance of the toilet. This is maybe the most important advantage of the UDDT. The smell problem mainly comes from the urine, poor cleanliness or wrong slope in the pipe (Matsebe, 2011).

The groundwater level is considered to be high if it is less than 2 meters below the surface. At this height it can interfere with the pit latrine, causing a lot of smell. A high groundwater level also means that the pit latrine has to be moved often, because it is impossible to dig a deep pit. In some areas, where the ground water level is only about $50 \mathrm{~cm}$ below the ground level in the rainy season. The pit latrine then has to move every 3 months. Such conditions prompted a higher interest in constructing a UDDT. It is in line with these results that UDDT in areas with high groundwater levels faced no acceptance problems (Shayo, 2003). 
A toilet close to the home is considered as being part of the home and therefore maintained and used better. The comfort for the owners is much higher as well which is of particular importance for women, children and old people. Although the re-use of the sanitation products is not a subject in this paper, a proper training on the safe handling and re-use of urine and treated feces is obligatory for a high sustainability.

\subsection{Maintenance of UDDT}

The maintenance was one of the main reasons many people dislike the UDDT and why others choose not to use it. Emptying the UDDT caused tensions in many households because the households were hesitant to handle the feces. A UDDT is slightly more difficult to keep clean compared to other toilets because of both the lack of water and the need to separate the solid feces and liquid urine. If not properly designed feces can be accidentally deposited in the urine section, causing blockages and cleaning problems (Mayo, \& Mubarak, 2015). All of the surfaces should be cleaned regularly to prevent odors and to minimize the formation of stains. Water should not be poured in the toilet for cleaning. Instead, a damp cloth may be used to wipe down the seat and the inner bowls. Some toilets are easily removable and can be cleaned more thoroughly. It is important that the feces remain separate and dry. When the toilet is cleaned with water, care should be taken to ensure that the feces are not mixed with water.

Because urine is collected separately, calcium- and magnesium-based minerals and salts can precipitate and build up in pipes and on surfaces where urine is constantly present. Washing the bowl with a mild acid (e.g., vinegar) and/or hot water can prevent the build-up of mineral deposits and scaling. Stronger (> 24\% acetic) acid or a caustic soda solution (2 parts water to 1-part soda) can be used for removing blockages. However, in some cases manual removal may be required. An odor seal also requires occasional maintenance. It is critical to regularly check its functioning.

Children above six years of could use UDDT toilet however. The participants complained that children failed in most cases to urinate and defecate in correct hole. Females, both young and old are mainly responsible for cleansing in the context of village. This would be the reason why young people were more accepting UDDT than the older people.

Lack of effective operation and maintenance (O\&M) is a major obstacle to achieving sustainable WASH in Schools programmes. It is often assumed that national and local governments take responsibility for a healthy school environment. However, it is often necessary to rely on students, teachers, parents and community groups for the improvement of the environmental situation at schools, including the operation and maintenance of school facilities. In planning for WASH in Schools, it is necessary to distinguish between capital costs and O\&M costs. Schools and communities may get some governmental or donor support to cover the capital costs although it is best when they also contribute to cover these costs. However, to ensure school sanitation programmes are sustainable, all operation \& management costs.

\subsection{Collaboration}

Implementing WASH in Schools in a comprehensive way requires the active involvement of a large number of groups and institutions. The parties involved could include the Ministry of education, Ministry of Health, Public Works Department, international organizations, NGOs and the Teachers Organization. At community and school levels, it should involve the headmasters, teachers, students and their parents and community organizations. Works in group and catch the sentiments of all stakeholder's is a great challenge. In the sense constructing Eco-san toilet and maintaining hygienic environment is not easily acceptable (Musingafi et al., 2015). 


\subsection{Location to construct UDDT}

For people with poor economic status and who have limited space the construction of pit latrines is a major issue. Due to often unhygienic situations, smell and problem with flies, the location of the pit latrines is far from the house and school. When introducing UDDTs people first are very skeptical about placing the toilet close to the house or even indoor because it can imagine that the technology is odor free and hygienic (ADVIES, 2012). Urine Diversion Toilet (UDT) Urine Diversion Dry (Dehydration) Toilet (UDDT).

\subsection{Improper Urine collection}

Urine is usually collected in containers with large volume next to the fecal chambers. Typical problem of urine collection chambers is overflowing. Sometimes urine pipe are not properly implemented with proper slope so that urine can stop in the pipe and start to smell. This can also lead to freezing in winter and thus blocking in the pipe. So this type of urine leakage problem (Mayo \& Mubarak, 2015).

\section{Discussion and Conclusion}

Eco-san represents paradigm shift about and acting upon human excreta. It is a 'closed loop' approach preventing pollution by recycling nutrients and organic matter. So, human excreta is proved itself as a resource not a waste. It is a safe approach to recovering nutrients from human excreta. It sanitizes excreta prior to recovery and reuse, and nutrients are recycled back into the land for productive purposes. Despite having some demerits, effective in water scarcity areas, safeguarding ground water contamination with pathogens and microorganisms and it has plenty of Nitrogen $(\mathrm{N})$, Phosphorus (P) and Potassium (K) called nutrient of crops are the major benefits of eco-san/UDDT. Addressing issues with pathogens and micro-pollutants in source-separated wastes by identifying and implementing ecologically-sound treatment processes that ensure 'safe reuse' of wastes as fertilizers is one of the best suggestions getting from the review. Eco-san and nutrient recovery technologies are perhaps inevitable changes to the way we perceive, manage and reuse our wastes. The pace and extent of its adoption and implementation however are aspects that remain to be seen.

Review related to challenges and gaps of eco-san and UDDT both conventional and alternative system found that source separation and reuse of waste fractions have had to encounter of overall sanitation in the world. It may not be only concern with ecology; it helps to promote overall public health and livelihood. The fore most challenges with UDDT are to make their use and maintenance simpler and thus more acceptable. Manual systems to enclose the feces and add cover material after each use felt uncomfortable. As users' perception, use of cover material, the removal and sensitization of excreta, and the sale fertilizers is still uncomfortable. This study has highlighted the lack of understanding about the use and benefits of the UDDT by many community members. Although the UDDT was used by $97 \%$ of respondents, there was a low level of acceptance and many aspired to have a flush toilet. Lack of education concerning the use of the UDDT was evident, as were problems with the quality of the UDDT materials. Community participation and provision of education about the use of the UDDT are important strategies in changing perceptions about ecological sanitation in eThekwini. Moreover, the current drought in South Africa is a reminder that waterborne sanitation is not a feasible option; the emphasis needs to be on community participation and education to counter perceptions of an inferior product, which improve acceptance, use and maintenance of the UDDT.

Despite of having demerits and gaps of Eco-san toilets, its application and knowledge transformation is must from schools to the community. As my field experience supports, participatory action research (PAR) is most suitable approach to transform its knowledge and 
its application to the wider community. Similarly, school curriculum reforms is required to incorporate the application of Eco-san/UDDT, water hygiene, school gardening through School Improvement Plan (SIP) and classroom pedagogy. Though Health education plays predominant role to promote our health, the Government of Nepal has given less value to Health education. In this sense, it needs to be made compulsory in the school curricula rather than eliminating from the national policy in formulating the law and incorporate it in School Improvement Plan (SIP) as well as implement it in the classroom.

\section{References}

Abraham, B., Kakumbi, G. M., Alam, M. M., \& von Muench, E. (2011). Alternative solutions for challenging environments: A look at UNICEF-assisted eco-san projects worldwide.

Adeoluwa OO, Cofie O. (2012). Urine as an alternative fertilizer in agriculture: effects in amaranths (Amaranthus caudatus) production. Renew Agric Food Syst 2012; 27:287e94. https://doi.org/10.1017/S1742170511000512

Adhikari, A. K., Acharya, H. N., Ahmad, T., \& Shrestha, S. (2017). Innovative sanitation social movement: experiences from Nepal.

Adhikari, K. (2015). Sanitation in Nepal: Past. Present and Future, 2nd edn, Kathmandu, Nepal: Kunti Bhoomi Memorial Trust.

Water-aid. (2008). Assessment of urine-diverting Eco-san toilets in Nepal. Nepal: Environment and Public Health organization

Bell, G. C. (2014). Annual report 2014.

Bonvin et al. (2015). Plant uptake of phosphorus and nitrogen recycled from synthetic source separated urine. Ambio 2015; 44:217-227. https://doi.org/10.1007/s13280-014-0616-6

Dreibelbis et al. (2013). The integrated behavioural model for water, sanitation, and hygiene: A systematic review of behavioural models and a framework for designing and evaluating behaviour change interventions in infrastructure-restricted settings. BMC Public Health, 13(1), 1015. https://doi.org/10.1186/1471-2458-13-1015

DWSS (2012). Country Paper on Sanitation in Nepal, in South Asian Conference on Sanitation SACOSAN, 2012, Local Government Division, Government of the People's Republic of Bangladesh.

Enerhall, C., \& Stenmark, E. (2012). Disc Filters to Reduce Wastewater Pathogen Levels in Raw Water Sources

Esrey, S., Gough, J., Rapaport, D., Sawyer, R., Simpson-Hébert, M., Vargas, J., \& Winblad, U. (1998). Ecological sanitation. Swedish International Development Cooperation Agency. Stockholm, Sweden

Heinonen-Tanski, H., Sjöblom, A., Fabritius, H., \& Karinen, P. (2007). Pure human urine is a good fertiliser for cucumbers. Bio resource technology, 98(1), 214-217. https://doi.org/10.1016/j.biortech.2005.11.024

Hu, M., Fan, B., Wang, H., Qu, B., \& Zhu, S. (2016). Constructing the ecological sanitation: a review on technology and methods. Journal of Cleaner Production, 125, 1-21. https://doi.org/10.1016/j.jclepro.2016.03.012

Kumwenda, S., Msefula, C., Kadewa, W., Diness, Y., Kato, C., Morse, T., \& Ngwira, B. (2017). Is there a difference in prevalence of helminths between households using 
ecological sanitation and those using traditional pit latrines? A latrine based cross sectional comparative study in Malawi. BMC research notes, 10(1), 200. https://doi.org/10.1186/s13104-017-2519-7

Matsebe, G. N. (2011). Perceptions of the users of urine diversion dry (UDD) toilets in medium density mixed housing in Hull Street, Kimberley (Doctoral dissertation)

Mayo A.W. \& Mubarak T. (2014). Challenges of adoption of urine- diversion dry toilets technology as sanitation option by coastal communities of Mkurange District in Tanzania. African Journal of Environmental Science and Technology, 9 (5), 482-492. DOI: 105897/AJEST2014, 1779 http://www.acdemicjournals.org/AJEST. https://doi.org/10. 5897/AJEST2014.1779

McConville, J. \& Rosemarin, A. (2012). The challenges of urban ecological sanitation: lessons from the Erdos eco-town project. Practical Action Publishers. ISBN 1853397687. https://doi.org/10.3362/9781780447674

Mkhize, N., Taylor, M., Udert, K. M., Gounden, T. G., \& Buckley, C. A. (2017). Urine diversion dry toilets in eThekwini Municipality, South Africa: acceptance, use and maintenance through users' eyes. Journal of Water, Sanitation and Hygiene for Development, 7(1), 111-120. https://doi.org/ 10. 2166/ washdev.2017.079

Musingafi, T., Musingafi, M. C., \& Kaseke, K. E. (2015). Challenges for ecological sanitation systems in urban areas: the case of Victoria ranch residential area, City of Masvingo. Public Policy and Administration Research, 5(6), 1-13.

Nyberg KA, Ottoson JR, Vinnerås B, Albihn A. (2014). Fate and survival of Salmonella Typhimurium and Escherichia coli O157: $\mathrm{H} 7$ in repacked soil lysimeters after application of cattle slurry and human urine. J Sci Food Agric 2014; 94: 2541e6. https://doi.org/10.1002/jsfa.6593

Ottoson, J. (2005). Comparative analysis of pathogen occurrence in wastewater: management strategies for barrier function and microbial control (Doctoral dissertation, KTH).

Rai, P., Sah, R. B., Rijal, R., \& Pokharel, P. K. (2015). Neglected scenario of sanitation in schools of Sunsari district of Nepal: Critical sphere for public health consideration. Health Renaissance, 13(2), 114-124. https://doi.org/10.3126/hren.v13i2.17560

Rajbhandari, K. (2008). Ecological sanitation latrines: The experience of Nepal. Beyond Construction use by all: A collection of case studies from sanitation and hygiene promotion practitioners in South Asia.

Rieck C., von Muench E., Hoffmann H. (2012). Technology Review of Urine-Diverting Dry Toilets (UDDTs). Overview of Design, Operation, Management and Costs. Eschborn, Germany

Rotter, J.B. (1982). Social Learning Theory. In N.T. Feather (Ed), Expectations and actions: Expectancy-value models in psychology (pp. 241-260). Hillsdale, NJ:Erlbaum

Rupakheti, S. (2013). Evaluation of Rural Sanitation Alternatives in Nepal Using Decision Support System (DSS) Approach.

Shayo, A. J. (2003, April). Acceptance of Eco-san concepts in Tanzania-a case study of piloting ecological sanitation, Majumbasita, Dar Es Salaam. In Eco-san-Closing the Loop. Proceedings of the 2nd International Symposium on Ecological Sanitation (pp. 07-11).

Shrestha, R. R., Shrestha, P., \& Shrestha, S. Sustainable Water Management Practice: A Case Study of Kathmandu 
Simha P. \& Ganesapillai M. (2016). Low-grade rock phosphate enriched human urine as novel fertilizer for sustaining and improving agricultural productivity of Cicer arietinum. https://doi.org/10.1016/j.spc.2016.01.005

Simha, P. \& Ganesapillia, P. (2017). Ecological sanitation and nutrient recovery from human urine: How far have we come? A review. Journal of Sustainable Environment Research 27 (2017) 107-116, www.journal.elsevier.com/sustainable-environment-research/ https://doi.org/10.1016/j.serj.2016.12.001

Snowdon, J.A., Cliver, D.O. and Converse, J.C. (1989). Land disposal of mixed human and animal wastes: A review. Waste Management and Research 7:121-134. https://doi.org/10.1016/0734-242X(89)90057-8

Stenström, T. A. (2001). Reduction efficiency of index pathogens in dry sanitation compared with traditional and alternative wastewater treatment systems. Internet Dialogue on Ecological Sanitation (15 Nov.-20 Dec. 2001).

Tilley, E. (2014). Compendium of sanitation systems and technologies. Eawag.

Von Muench, E., \& Winker, M. (2011). Technology review on urine diversion componentsOverview of urine diversion components such as waterless urinals, urine diversion toilets, urine storage and reuse systems. Gesellschaft für Internationale Zusammenarbeit (GIZ) $\mathrm{GmbH}$.

Wendland, C., Deegener, S., \& Jorritsma, F. (2011). Experiences with urine diverting dry toilets (UDDTs) for households, schools and kindergarten in Eastern Europe, the Caucasus and Central Asia (EECCA). Sustain. Sanit. Pract, 6, 16-22

Wilbur, P. A. M. (2014). An evaluation of the use of composting latrines and the perceptions of excrement in Ngäbe communities in Panamá.

Winblad, U., Simpson-Hébert, M., Calvert, P., Morgan, P., Rosemarin, A., Sawyer, R., \& Rapaport, D. (2004). Ecological sanitation.

World Health Organization, \& UNICEF. (2017). Progress on drinking water, sanitation and hygiene: 2017 update and SDG baselines.

Yongha Boh M, Germer J, Müller T, Sauerborn J. (2013). Comparative effect of human urine and ammonium nitrate application on maize grown under various salt concentrations. $\mathrm{J}$ Plant Nutr Soil Sci 2013; 176: 703e11.https://doi.org/10.1002/jpln.201200486 https://doi.org/10.1002/jpln.201200486 